\title{
Thermal, Mechanical and Electrontransport Properties of Irradiated Rapidly Solidified Pb-Sn-Zn Alloy
}

\author{
A.M. Shaban ${ }^{1}$, M. Kamal', \\ 1- Metal Physics Lab, Physics Department, Mansoura University, \\ Mansoura, Egypt. \\ R.H. Nada ${ }^{2}$, M.M. El-Sayed ${ }^{2}$ and F. Abd El-Salam ${ }^{2}$ \\ 2 - Department of Physics, Faculty of Education, Ain Shams University, \\ Cairo, Egypt.
}

\begin{abstract}
The effect of gamma irradiation on the thermal, mechanical parameters and electrical properties of $\mathrm{Pb}-5 \mathrm{wt} . \% \mathrm{Sn}-0.5 \mathrm{wt} . \% \mathrm{Zn}$ alloy rapidly solidified from the melt was investigated. The results showed irregular behaviour of the parameters measured for samples irradiated with doses up to $200 \mathrm{KGy}$. Above $200 \mathrm{KGy}$ a clear trend of variation tooks place. The values of the specific heat under constant pressure $C_{P}$ and the activation energy of ordering, $U$, showed opposite behaviours above 200KGy, up to 1 MGy. The deterioration of the elastic modulus and internal friction properties caused by irradiation appear to have a bad potential for using the present alloy as structural material soldering alloy in nuclear structures. The increased resistivity with irradiation was rendered to the increased scattering of transport electrons caused by the created scattering centres induced by gamma-rays.
\end{abstract}




\section{1 - Introduction:}

The wide use of lead-tin base alloys justifies their further investigations. Rapid solidification from the melt produces solid tapes of amorphous and fine microstructure suitable for investigating the mechanical properties[1]. These tapes show improved ductility, formability, stress corrosion life and fracture toughness [2].

$\mathrm{Sn}$ content in $\mathrm{Pb}-\mathrm{Sn}$ alloys used in acid-battery applications was found [3] to increase the electronic conductivity sharply when alloying tin content is increased from 0.8 to $1.5 \mathrm{wt} . \%$. The electrical resistivity variations of rapid solidified $\mathrm{Pb}-10 \mathrm{wt} . \%$ Sn soldering alloy were used to estimate the solid mass fraction as a function of temperature [4]. The equilibrium phase diagram of the $\mathrm{Pb}-\mathrm{Sn}$ system was investigated using differential thermal analysis (DTA) technique [5]. The results show a clear eutectic effect within $\pm 2 \mathrm{~K}$ of the eutectic temperature, 456K. By using the mechanical analogue model [6], it was found that the width of the sliding-no sliding transition is governed by a power law. An estimate of the interphase diffusivity based on the sliding viscosity provides a value that is 1-2 orders of magnitude higher than that based on the boundary diffusion data.

In spite of the tremendous progress that has been made in the discipline of irradiated ingots rapidly solidified from melt, there still remains lack of information about the development of even more sophisticated and specialized soldering materials $[7,8,9]$.

The aim of the present work is to investigate the effect of $\gamma$-irradiation on the mechanical, thermal and electrical properties of rapidly solidified $\mathrm{Pb}-5$ wt.\% Sn- 0.5 wt.\% Zn. alloy at different temperatures.

\section{2 - Experimental Procedure:}

\section{1 - Sample preparation:}

Samples of $\mathrm{Pb}-5 \mathrm{wt} . \% \mathrm{Sn}-0.5 \mathrm{wt} \% \mathrm{Zn}$ alloy rapidly solidified from the melt were obtained by using a single aluminium roller $(20 \mathrm{~cm}$ in diameter at a constant speed of $30.4 \mathrm{~m} \mathrm{~s}^{-1}$ ). In such technique the cooling rate is assumed to be very high, about $10^{6} \mathrm{~K} \mathrm{~s}^{-1}$, due to the small thickness of the produced ribbons and the high velocity of roller. Full details of sample preparation, procedure and techniques are published elsewhere [10]. The prepared samples were irradiated to different doses up to $1 \mathrm{MGy}$. Irradiation of specimens was carried out in air, at room temperature and with a dose rate of $0.9 \mathrm{~Gy} \mathrm{~s}^{-1}$ by using a $\mathrm{Co}^{60}$ source from a gamma-rays chamber. 


\section{2 - Mechanical properties:}

According to the improved measuring system suggested previously [11], a modified dynamic resonance vibrator as that published elsewhere [12] was used to study the mechanical behaviour of the investigated samples. The amplitude of vibration against the frequency of vibration, around the resonance frequency $F_{0}$, gives the resonance curve which characterize the mechanical resonance of the sample. From the resonance curve, the internal friction, $\mathrm{Q}^{-1}$, and the dynamic elastic modulus, E, were obtained from the following relations [13]:

$$
Q^{-1}=0.5773 \frac{\Delta \mathrm{F}}{\mathrm{F}_{\mathrm{o}}}
$$

where $\Delta \mathrm{F}$ is the full width at half maximum amplitude, and

$$
\left(\frac{E}{\rho}\right)^{\frac{1}{2}}=\frac{2 \pi \mathrm{L}^{2} \mathrm{~F}_{o}}{\mathrm{KZ}^{2}}
$$

where $\rho$ is the density of the sample under test, $L$ is the length of the vibrating part of the sample, $\mathrm{K}$ is the radius of gyration of cross section perpendicular to its plane of motion, and $\mathrm{Z}$ is a constant depends on the mode of vibration and assumes the value of 1.851 [14].

\section{3 - Differential thermal analysis :}

The differential thermal analysis (DTA) data were obtained by using Shimadzu thermal analyzer, DT-30. The heating cell was two platinum crucibles one of which contained the reference material while the other contained the specimen under test. The specimen weight was about $20 \mathrm{mg}$. The heating rate was kept constant at $10 \mathrm{~K} \mathrm{~min}^{-1}$ in the temperature range $300-600 \mathrm{~K}$.

The specific heat under constant pressure $\left(\mathrm{C}_{\mathrm{p}}\right)$ obtained from the DTA thermograms by using the relation [15]:

$$
C_{P}=\frac{\mathrm{Q}}{\mathrm{MT}_{\mathrm{m}}}
$$

where the energy Q dissipated through the sample is proportional to the area under the DTA curve deviated from the base line, $M$ is the mass of the sample and $\mathrm{T}_{\mathrm{m}}$ is the melting temperature of the sample. 


\section{4 - Electrical measurments:}

The electrical measurments at different temperatures for the investigated samples were made by using the four prope Kelvin Double-Bridge methed. The variation of the temperature, was carried out by a step-down transformer connected to a constructed temperature controller. The heating rate was kept constant at $10 \mathrm{Kmin}^{-1}$. The specimen temperature was measured by Beckman Industrial TP850 digital thermometer.

\section{3 - Results and Discussion:}

The irradiation dose dependence of the elastic modulus of the investigated samples is demonstrated in Fig. (1a). A sharp drop of the dynamic Young's modulus at $20 \mathrm{KGy}$ is followed by an increase to a peak value at 100 KGy irradiation dose. Further increase of irradiation dose decreases the modulus and above $200 \mathrm{KGy}$ it shows slight increase. Clustering of the initially irradiation induced defects may take place and this reduces the number of dislocation pinning points leading to the observed decrease of the dynamic Young's modulus (E), and the increase of the internal friction $\left(\mathrm{Q}^{-1}\right)$.

At $100 \mathrm{KGy}$, the free induced defects increase the number of dislocation pinning points which harden the alloy, and this, as shown in Fig.1, increases the dynamic Young's modulus (E) and decreases the internal friction $\left(\mathrm{Q}^{-1}\right)$. To fit the experimental data of Fig.1, it is assumed that the probabilty of clustering of the defects produced by the 200 KGy dose, is higher than that produced at $20 \mathrm{KGy}$, This decreases the density of the

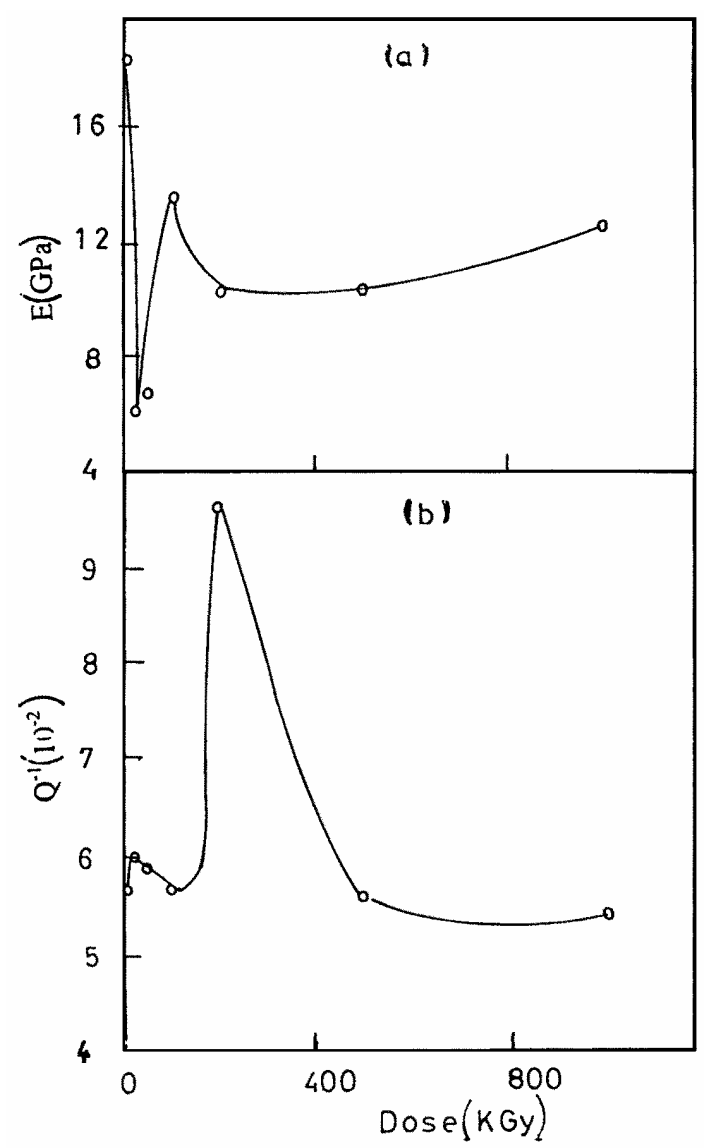

Fig. (1) Dependence of:

a) dynamic elastic modulus (E).

b) internal friction $\left(Q^{-1}\right)$. on the irradiation dose of $\gamma$-rays 
pinning points for dislocations and consequently decreases the stiffness of the alloy and decreases $\mathrm{E}$ and increases $\mathrm{Q}^{-1}$ values. The increased density of the induced irradition defects (above $200 \mathrm{KGy}$ ) increases dislocation pinning as indicated by the relative increase of $(\mathrm{E})$ and the decrease in $\left(\mathrm{Q}^{-1}\right)$ values.

Figure 2 shows the temperature dependence of the specific heat under constant pressure, $\mathrm{C}_{\mathrm{p}}$, for samples irradiated with different doses. The irradiation dose dependence of the maximum specific heat under constant pressure $\mathrm{C}_{\mathrm{p}}$ max. , as obtained from Fig. (2), is given in Fig. 3a. Both the liquidus temperature $T_{L}$ and the solidus temperature $T_{s}$ are displayed, in Fig. (3b,c). Two peaks are observed in Fig. (3a), an initial sharp peak at 50 KGy followed by a drop to nearly the original value, then a peak at $200 \mathrm{KGy}$, followed by a continuous decrease with irradiation dose up to $1 \mathrm{MGy}$. At $200 \mathrm{KGy}, \mathrm{T}_{\mathrm{s}}$ increases to a high value and $\mathrm{T}_{\mathrm{L}}$ reaches its maximum value. The change of specific heat $\Delta \mathrm{C}_{\mathrm{p}}$ with increasing temperature obeys the experimental low [16].

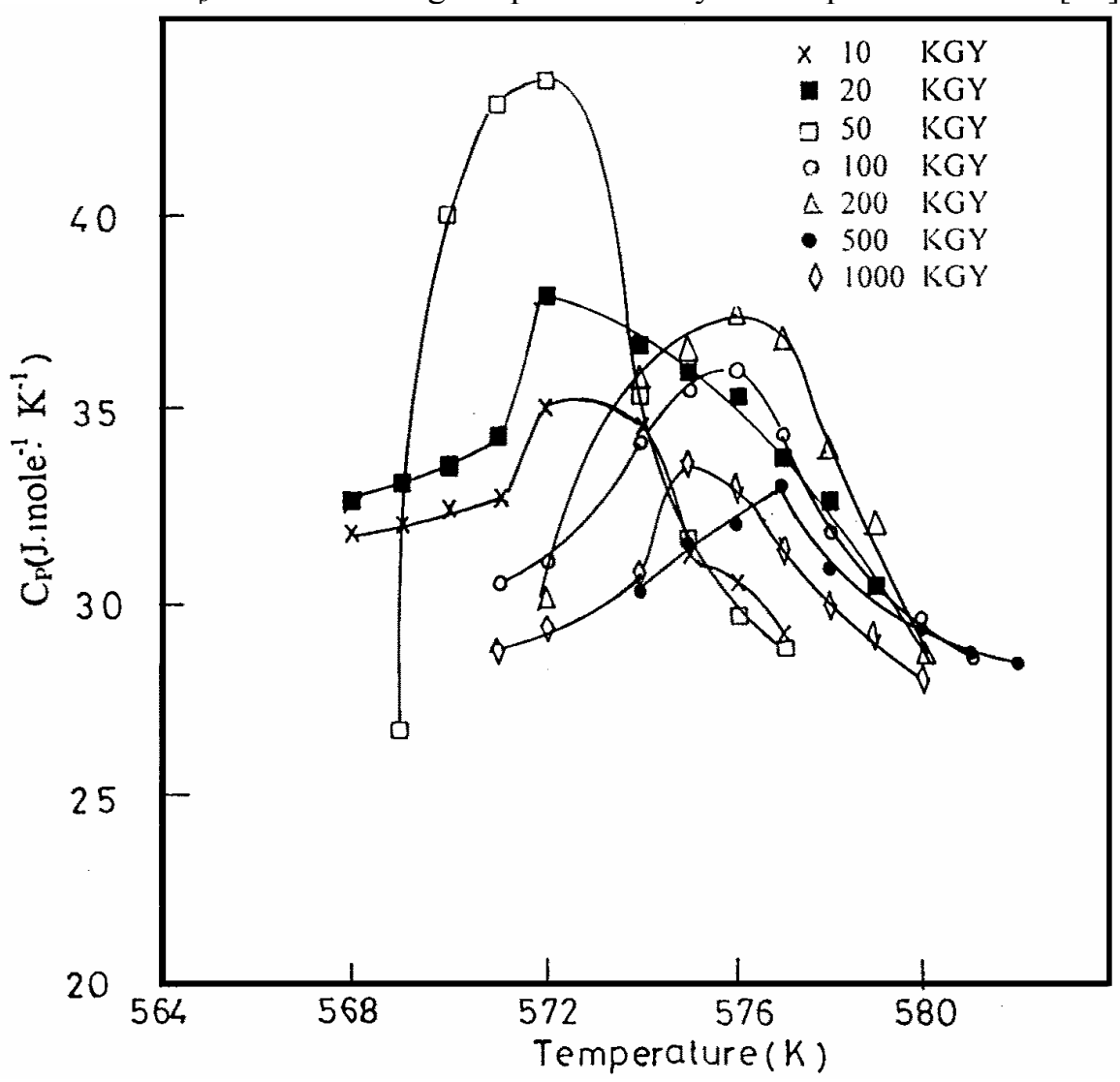

Fig. (2): Temperature dependence of specific heat at constant pressure $C_{p}$.

$$
\Delta \mathrm{C}_{\mathrm{p}}=\mathrm{A}\left(\mathrm{NU}^{2} / \mathrm{RT}^{2}\right) \exp (\mathrm{U} / \mathrm{RT})
$$


where $\mathrm{N}$ is the number of atoms displaced from the equilibrium position, $\mathrm{U}$ is the activation energy of ordering transition, $\mathrm{R}$ is the universal gas constant and $\mathrm{A}$ is the coordination number. Irrespective of the value of the pre-exponential term the relation between $\ln \left(\Delta \mathrm{C}_{\mathrm{p}} \mathrm{T}^{2}\right)$ and $1 / \mathrm{T}$ for the alloy samples irradiated to different doses should give straight lines as those shown in Fig.4. The slopes of the straight lines of Fig. (4), give the activation energy of ordering. The irradiation dose dependence of the activation energy $U$ is given in Fig. (5a). It is clear that the value of the energy of ordering $\mathrm{U}$, increases at $50 \mathrm{KGy}$, then decreases at 100KGy and gradually increases again up to 1 MGy. From Figs(3a) and (5a), the decrease of $\mathrm{C}_{\mathrm{p}}{ }^{\max }$ above $200 \mathrm{KGy}$ corresponds to an increase in the energy $U$. The variation of the relative change of the activation energy of ordering $\frac{\Delta U}{U_{o}}$, where $\mathrm{U}_{\mathrm{o}}$ is the value of the activation energy of ordering for the sample irradiated to $10 \mathrm{kGy}$ dose, with the irradiation dose is shown in Fig. $5 \mathrm{~b}$. It is clear that $\frac{\Delta U}{U_{o}}$ increases at $50 \mathrm{KGy}$ then drops to a minimum at $200 \mathrm{KGy}$ after which it increases again gradually up to a maximum value at $1 \mathrm{MGy}$.

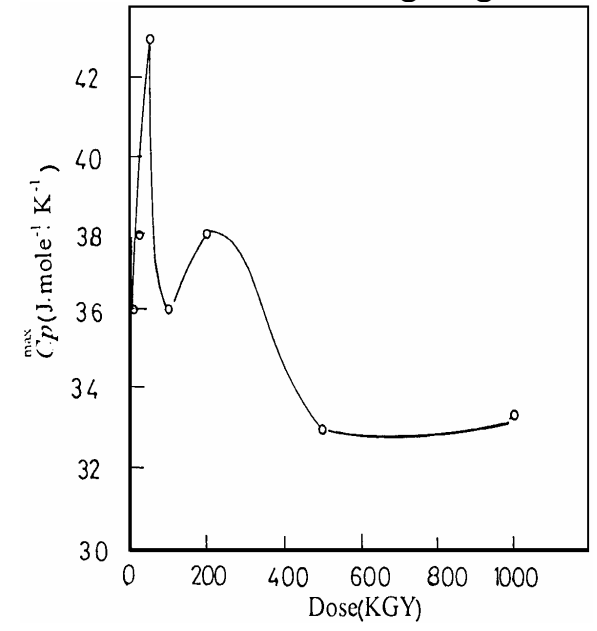

Fig. (3a) : The maximum specific heat at constant pressure $\mathrm{C}_{\mathrm{p}}{ }^{\max }$ dependence on irradiation dose.

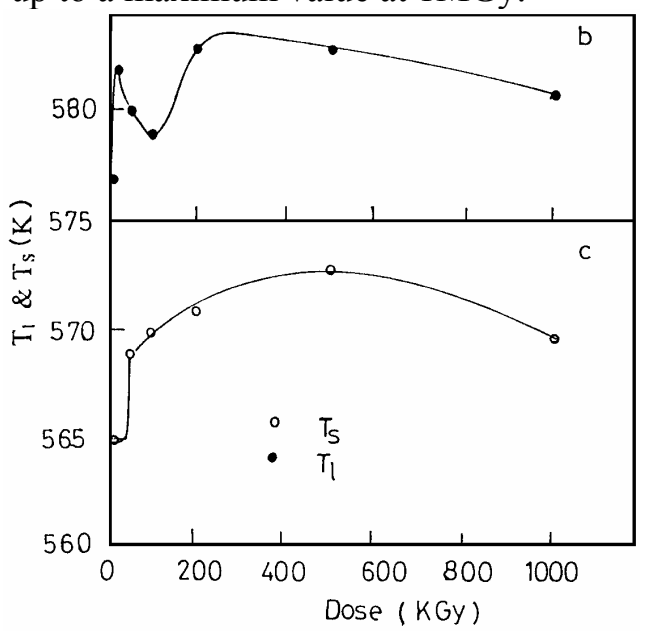

Fig. (3 b,c): Variation of liquidus temperature $T_{L}$ and solidus temperature $T_{\mathrm{s}}$ with irradiation dose.

The softning at $50 \mathrm{KGy}$ observed in Fig. 1, showing itself as a decrease in $\mathrm{E}$ and increase in $\mathrm{Q}^{-1}$ consists with the increased absorbed energy, Fig (5a), required to activate the dislocation movements taking place in this state. The reduction of such movements at $100 \mathrm{KGy}$ agrees with the observed increase of E shwon in Fig. 1, and referes to the minimum energy required as shown in Fig. (5a). 


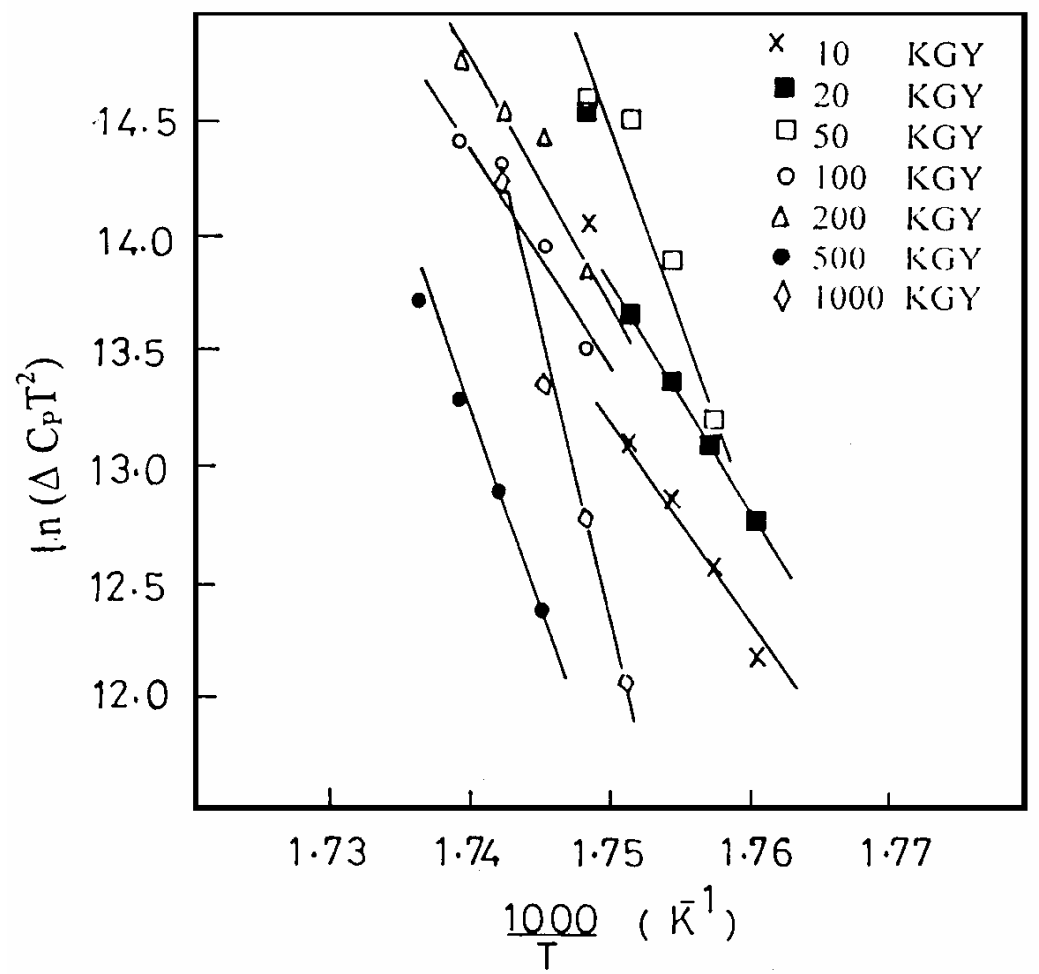

Fig. (4): The $\ln \left(\Delta \mathrm{C}_{\mathrm{p}} \mathrm{T}^{2}\right)$ Value against $1 / \mathrm{T}$ at different irradiation dose.
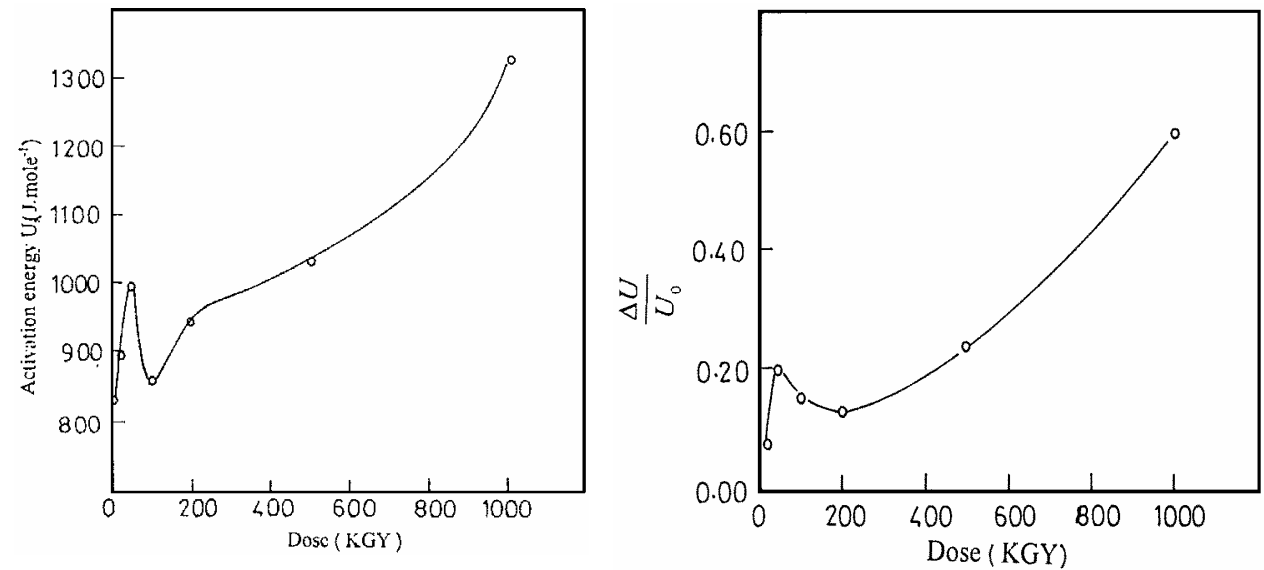

Fig. (5a) The variation of activaton energy of ordering $\mathrm{U}$ with irradiation dose.

Fig. (5b) The relative change of activation energy of ordering $\frac{\Delta U}{U_{o}}$ as a function of irradiation dose.

Figure 6, shows the temperature dependence of the electrical resistivity of the alloy samples irradiated with different doses. In general, continuous increase of resistivity is observed with increasing temperature and/or irradiation 
dose. The increase in resistivity may be due to the increase of the existing defects, and their thermally activated diffusion in the alloy components.

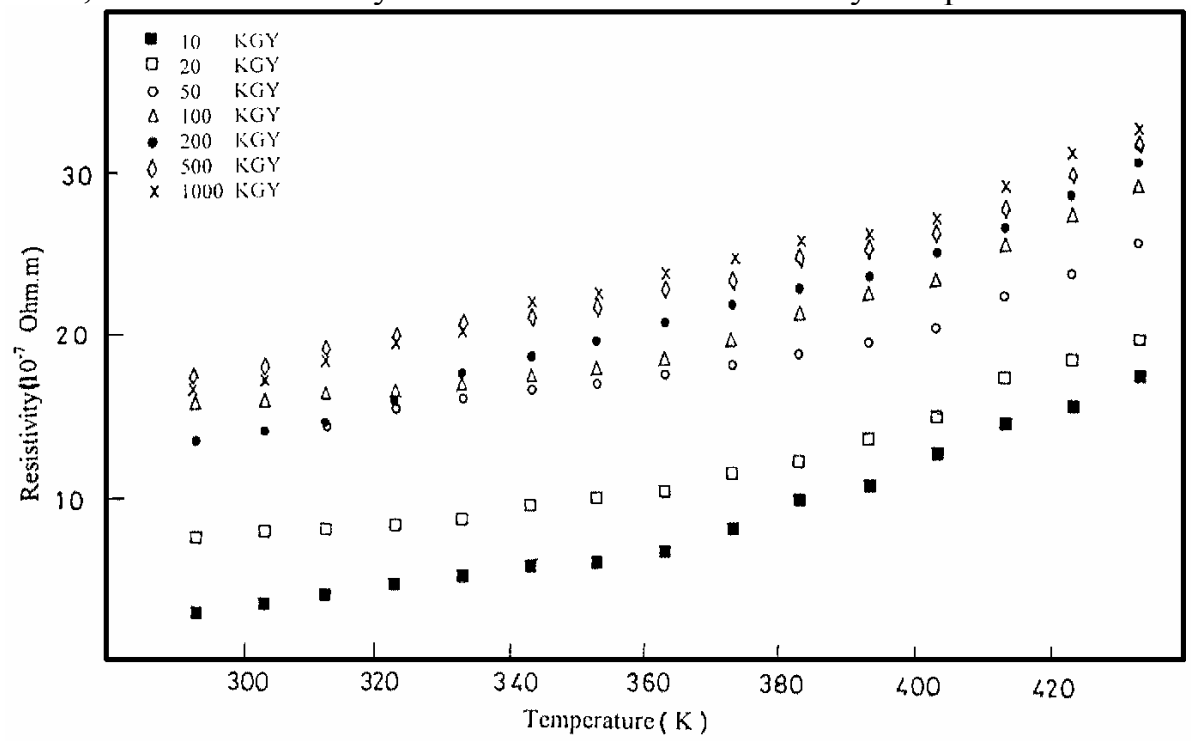

Fig. (6): The electrical resistivity as a function of the temperature at different irradiation doses.

The influence of gamma-rays irradiation on the studied thermal, mechanical and electrontransport properties can be attributed to the creation of defect centres with inhomogeneous distribution. Low density of these centres is created at low gamma-ray irradiation dose. This density increases with the increase of irradiation dose, which creates more defect centres.

\section{Conclusions:}

From the foregoing analysis of the results obtained for the rapidly solidified $\mathrm{Pb}-5 \mathrm{wt} \%$ - Sn 0.5 wt.\% $\mathrm{Zn}$ alloy, the following conclusion may be drawn:

1 - Thermal, mechanical and electrontransport properties are very sensitive to ionizing radiation.

2 - The deterioration of the elastic modulus and internal friction properties caused by irradiation appears to have a bad potential for using the present alloy as structural material soldering alloy in nuclear structures.

3 - The activation energy of ordering $U$ and specific heat under constant pressure $C_{p}$ are inversly affected above $200 \mathrm{KGy}$ irradiation dose. 
4 - The electrical resistivity of the studied alloy depends on irradiation dose due to the increase of the disordered scattering of transport electrons caused by the Scattering creeted by gamma-rays irradiation.

\section{References:}

1. M. Kamal, A. B. El-Bediwi, J. Mater. Sci. Materials in Electronics, 11, 519 (2000).

2. A. M. Abd El-Khalek, Arab Journal of Nuclear Sciences and Applications, 215 (2002).

3. P. Simon, N. Bui, N. Pebere and F. Dabosi of Power Sources, 53, 1, 163 (1995).

4. S. H. Liu, D.R. Poirier and P.N. Ocansey, Metall. Mater. Trans. A, Phys. Metall. Mater. Sci., 26A, 3, 741 (1995).

5. B. Sprusil, J. Burianck and B. chalupa, phys. status solidi A, 147, 1, 7 (1995).

6. S.M. Lee and D.S. Stone, Scr. Metall, Mater., 30, 9, 1213 (1994).

7. A. M. Shaban, Radiation effects and defects in solids, 133, 51, (1995).

8. A. M. Shaban and M.Kamal, Radiation effects and defects in solids, 133, 5 (1995).

9. A.M. Shaban, M.M. El-Sayed, M. El-Kady and M. Kamal, AMSE, Modelling, Measurment and control, C., 54, 2, 31, (1996).

10. M. Kamal, J. C. Pieri and R. Jouty, Mémoires et Etudes Scientifiques Revue de Metallurgie-Mars, 143 (1983).

11. S. Spinner and W.E. Teffit, Am. Soc. Test. Mater. Proc., 61,1221 (1961).

12. M. Kamal, A. M. Shaban, M. El-Kady and R.Shalaby $2^{\text {nd }}$ Int. Conf. On Eng. Math. and Phys., Cairo, 2, 107-121 (1994) (ICEMP-94).

13. J. Flores-Maldonado, S. Galindo and H. Jinerez-Dominignez, Am. J. Phys. 55, 664(1987).

14. A.Y. Malkin, A.A. Askadsky, V.V. Kovriga and A.E. Chalykh, Experimental Methods of polymer Physics, Mir Publishers, Moscow, 213 (1983).

15. M. Amin, H. Osman, S.E. Gwaily and E. El-Feki, K Fac. Educdcation, Ain Shams University. Egypt, No. 19, Part III, 919-930 (1994).

16. V. P. Burtsera, S.E. Vasil and U.M. Varirash, Sov. Phys. Solid State, 30, 877 (1988). 